\title{
Modification of Clamping System Designated for Automatic Workpiece Exchange
}

Matej Kandera, Miroslav Císar, Ivan Kuric

University of Žilina, Faculty of Mechanical Engineering, Department of Automation and Production Systems, Univerzitná 1, 01026 Žilina, Slovakia. E-mail: Matej.Kandera@fstroj.uniza.sk, Miroslav.Cisar@fstroj.uniza.sk, Ivan.Kuric@fstroj.uniza.sk

\begin{abstract}
Automatic workpiece exchange is one of the important parts of every flexible manufacturing system. This part largely allows complete automation of the component's production cycle. It also greatly contributes to a significant reduction in the workpiece clamping times and contribute to a reduction in the downtime during the machining process. It also allows eliminating a human factor from the production process, thereby contributing to greater machine utilization and higher machining productivity. This article describes certain modifications of interchangeable pallet system designated for specific training CNC machine tool EMCO Concept Mill 105 situated in the laboratory at the Department of Automation and Production Systems. This machine has considerably limited workspace and length of feeds which are the most limiting parameters during design. Mentioned modifications allow manipulating with designed pallets with the industrial robot or special manipulator instead of previously designed manual handling.
\end{abstract}

Keywords: workpiece exchange, interchangeable pallets, quick-charge pallet system

\section{Introduction}

As a definition say, a technological pallet is a quickly removable indexed machining fixture that is used when the maximum productivity of machined parts is required. The use of multiple pallets reduces machine "down time" drastically and makes the machined parts cost-effective when quantities are large enough to warrant a palletizing system. So, the most significant use of technological pallets is in serial production. In a palletized system, the machine operator loads multiple parts into different pallets while the machine tool is machining parts on another pallet which was loaded previously. All the pallets are pin indexed to perfectly fit the position on a worktable of the machine tool at a precise location relative to the defined zero position. In effect, the machine operator is using the time while the $\mathrm{CNC}$ machine tool is machining, to load another pallet outside of the machine tool. [1]

When we talk about automatic workpiece exchange two most common techniques are known. The first one requires clamping workpieces on a technological pallet with which is subsequently manipulated. The second technique is based on the clamping of the workpiece directly on the machine tool worktable without the use of any technological pallets as a coupling constructional node. Both of these methods have its own advantages and disadvantages which should be carefully considered together with requirements of the desired application. [2]

Also, principles using interchangeable pallet systems can be divided into several known groups, according to the pallet exchange method, pallet arrangement at the workplace, and equipment of the production machine. Mentioned groups include systems with two pallets, systems with pallets held on indexing table, systems with pallets storage carousel and usage of specially designed manipulators or industrial robots. [3]

This article presents modifications of the design of interchangeable technological pallets system designated for CNC machine tool Emco Concept Mill 105 (CM 105).
This CNC machine is small milling machine tool with three controlled axes designed especially for industrial training and it's available in the laboratory of CNC machine tool programming at the Department of Automation and Production Systems, Faculty of mechanical engineering, University of Žilina. Mentioned modifications or improvements permit the machine to perform a fully automated process of machining and to connect the machine to the flexible production cell.

\section{The initial design conditions}

Mentioned system of exchangeable technological pallets, is designed for Emco Concept Mill 105, which is an educational machine tool. As its manufacturer says it is a PC- controlled CNC- table- machining center for milling, drilling and tapping with interchangeable control-specific key module. The machine is available with fully enclosed working area, safety units according to CE- regulations, 10- station tool drum, central lubrication system, machine lamp, electrical and mechanical preparation for automation and tool-set for operation. So called "robotic interface" allows integration to Flexible manufacturing systems and CIM and it ensure connecting machine with other machines or devices such as robots. Then DNC interface allow this machine to be integrated into flexible manufacturing system (FMS) and to be condtrolled from central personal computer. [4, 5]

Except of attributes and advantages mentioned above, this machine has also some disadvantages. Since it is an educational CNC machine designated mainly just to provide real life example of machining and $\mathrm{CNC}$ programming, and i tis not ment to be used as a production machine. This model has a considerably limited workspace and power is intended for machining soft materials such as aluminum and plastics. Due to mentioned parameters of chosen machine tool, the design was focused mainly on its workspace and lengths of feed, which was the main limiting attributes. $[6,7]$

Designed system consists of three main constructional 
nodes (Fig. 1). First of all is a mounting base, which is part of construction that connects and mounts the system of technological pallets on the machine worktable. Great emphasis is placed on the accuracy and stiffness of the entire system, when placing and clamping the workpieces, so it is necessary that mounting base also fulfil these requirements. Second part is pallet mounting mechanism. There was chosen specific so-called zero-point system with very small proportions but sufficient clamping forces and accuracy to perfectly fit this application. Last, but not the least part of design is the technological pallet itself. Design of this pallet uses uncommon non-flat shape which was precisely adjusted for this specific application and milling machine. $[8,14]$

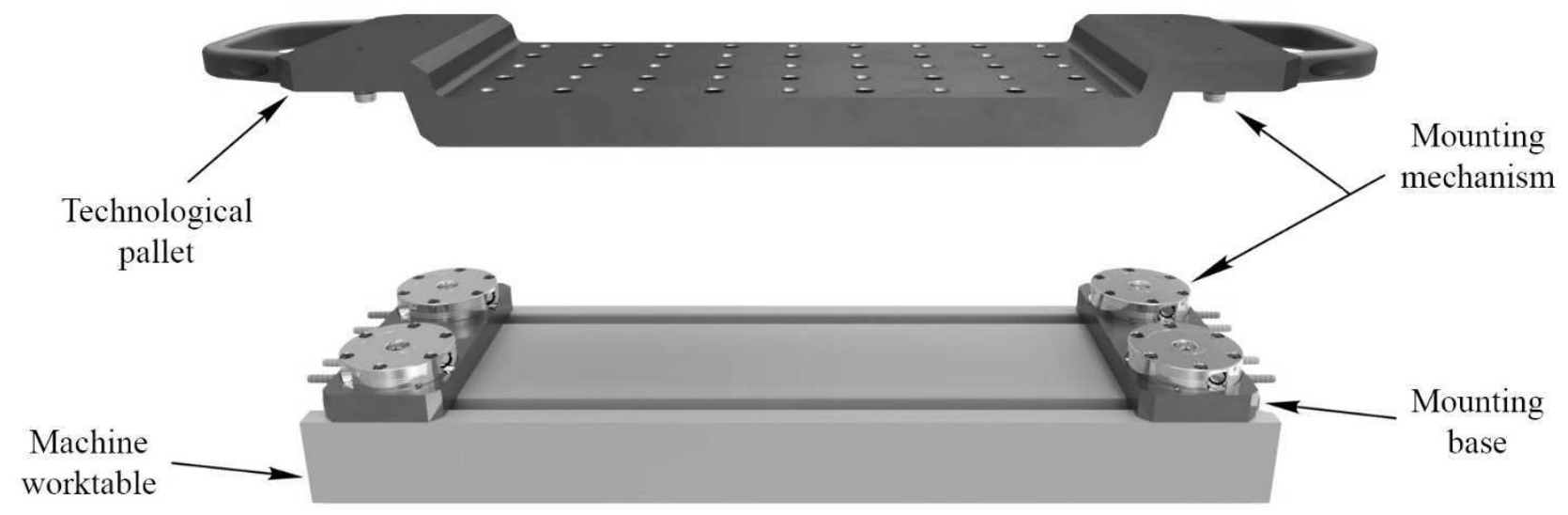

Fig. 1 Main constructional nodes of designed pallet system

In the described design, pallet can be easily manipulated using ergonomic handles on both sides of each pallet. However, manual manipulation cannot be part of the desired implementation into a complex flexible manufacturing system or flexible production cell. Because of this reason, it is necessary to modify system design, which have to follow these basic requirements:

- It should allow easy and fast pallet exchanging by robot,

- it should be designed in such a way that there is no need to significantly change the size and shape of the designed pallet and ensure retain of the overall height of the system.

\section{Modifications of design}

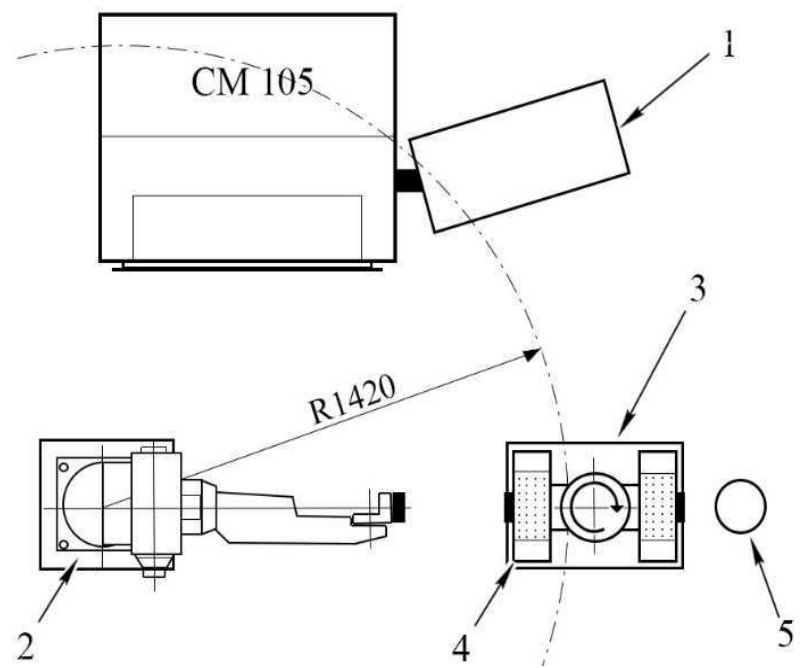

Fig. 2 Scheme of described flexible mproduction cell: 1Control panel, 2- Industrial robot, 3-Indexing table, 4Pallet, 5-Machine operator position.
The application of workpiece clamping system using technological pallets equipped with fixed handles which are designed for manual handling, represents a certain improvement, compared to classic methods of workpiece clamping directly on worktable or in vise currently used in laboratory. However, this system can't be further implemented into flexible manufacturing cell or flexible manufacturing system generally because it would require automatic manipulation with pallets. Therefore, the original design has to be modified.

The interchangeable technological pallets system is designed in order to allow integration of EMCO Concept Mill 105 (CM 105), as part of flexible manufacturing cell, into FMS. The scheme of desired part of FMS with the mentioned machine with its main parts and equipment is in the Fig. 2.

The main part of the designed flexible manufacturing cell (Fig. 2) is the milling machine CM 105, which is equipped with additional table. A control panel (1) is placed on this table along with a monitor and an additional mouse and keyboard. Next major element of the workplace is the industrial robot (2). In this case it is Fanuc M$10 \mathrm{iA} / 12$ which was selected because of its maximum payload of $12 \mathrm{~kg}$, maximum reach of its arm $1420 \mathrm{~mm}$, and kinematice sufficient for application. In the previous scheme, a fixed robot is counted but if its needed it could be mounted on a mobile platform, which would allow it to move between the individual positions within the workplace. The last from three major parts of this cell is rotary pallet changer or indexing table (3) with pallets. This table is also a workplace of the operator, whose task is to clamp and remove workpieces from technological pallets before and after machining. The indexing table is rotated by $180^{\circ}$ during each cycle. It has two positions, one in which the pallet is taken with the workpiece and second in which the operator of this workplace removes finished parts and clamps the new workpieces on the 
pallet. $[9,10]$

Due to the requirements, modifications of proposed design of interchangeable pallets system (Fig. 3) involves these steps:

- selecting a suitable robot coupling system,
- modifying construction of the technological pallet itself with respect to the used manipulating system,

- designing of robot flange, which is necessary for attaching coupling system on robot's end of arm.

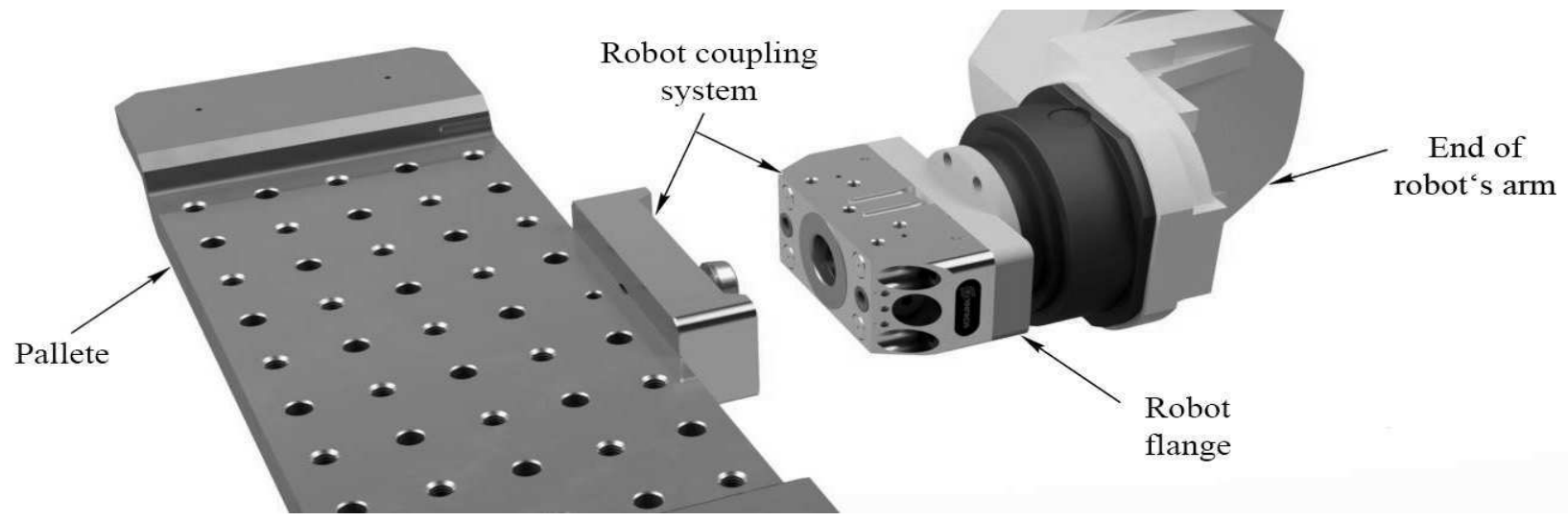

Fig. 3 Main parts of modified interchangeable pallet system

\subsection{Robot coupling system}

For this specific application, due to the construction and dimensions of the machine on which is the system of automatic workpiece exchange planned to be implemented, seems like the optimal solution to prefer robot with a serial kinematic structure or specially designed manipulating device. However, since the design and development of such a manipulating device would deliver considerably higher time and financial costs and currently available robots with serial kinematics perfectly satisfy early defined requirements. Based on these findings, the implementation of an industrial robot was proposed.

First of all, it is necessary to choose suitable method of clamping of technological pallets with the robot. For this purpose, Schunk Vero-S NSR mini 100 robot coupling system was chosen. The suitability for use of this system is also dependent on the calculation of the maximum torque generated in the coupling $\mathrm{Mx}$ and $\mathrm{Mz}$ (Fig. 4). These are calculated from the formula described in the operating manual by the manufacturer and must not exceed the maximum allowed values. Calculation includes the following variables: weight of the load (pallet coupling PKL mini 100, clamping pallet and transport load), effective lever length from the coupling interface between the robot coupling and pallet coupling to the center of gravity of the load, acceleration due to gravity and maximum acceleration of robot arm. Since in our case there is a robot load capacity limit $(12 \mathrm{~kg})$ far below the allowed maximum load of the coupling system $(75 \mathrm{~kg})$, the maximum torque will not occur under any reasonably achievable conditions. [11]

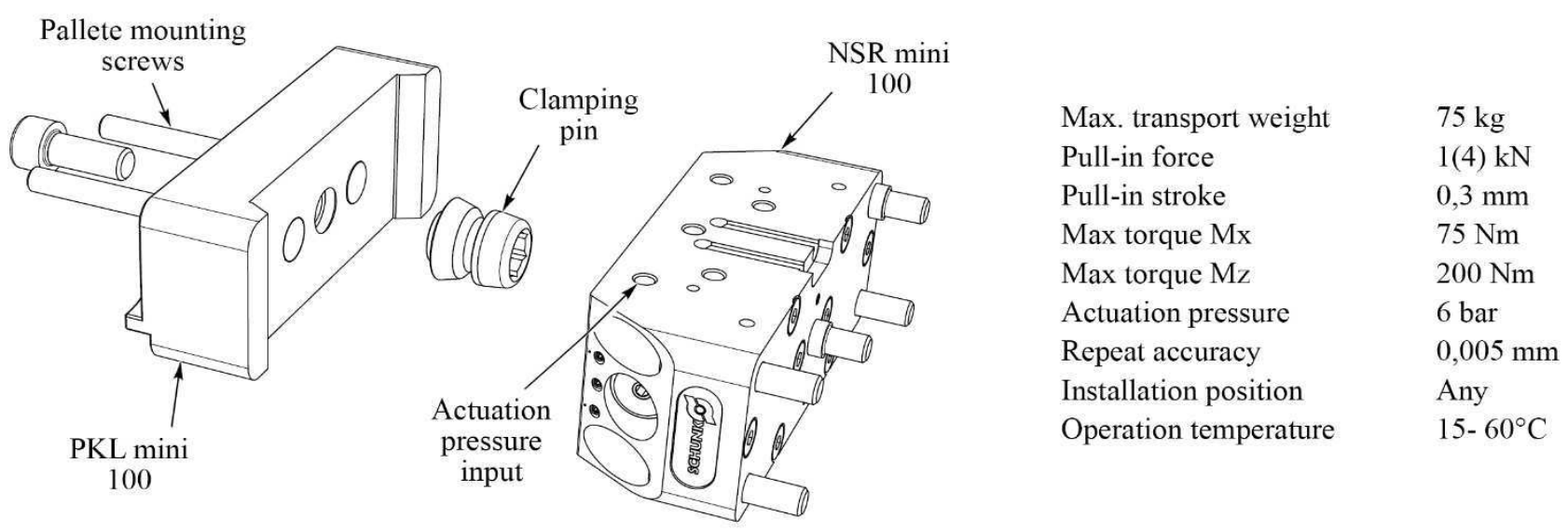

Fig. 4 Specifications of Schunk Vero-S NSR mini 100 robot coupling system

Vero-S NSR mini 100 consists of two main parts. First is pallet coupling PKL mini 100 which is fixed to the technological pallet and the other, robot module NSR mini 100 , fixed to the end of robot's arm. The clamping procedure is performed based on an integrated spring assembly. The force transmission occurs based on patented drive kinematics which transmits the available spring force into a maximum pull-down force at the clamping pin. The clamping is self-retaining and the pull-down force can be increased with the help of an integrated turbo function. Opening is solved pneumatically with 6 bar system pressure. Presence of the clamping pin and hence the 
presence of a pallet is monitored by an inductive proximity switches implemented in robot coupling system [12, 13].

\subsection{Robot flange}

Since this system is universally applicable to different types of robots from different manufacturers, it's necessary to attach coupling system by flange specific for the chosen robot. Shape and dimensions of the designed flange are partially determined by the shape of chosen coupling system and especially by the layout of its clamping elements. This flange should provide an accurate and reliable coupling connection between coupling system and industrial robot. The model of such flange is shown in Fig. 5. It consists of two parts set up by two cylindrical pins and secured by Allen screws M6 x 16 STN 021143.52.

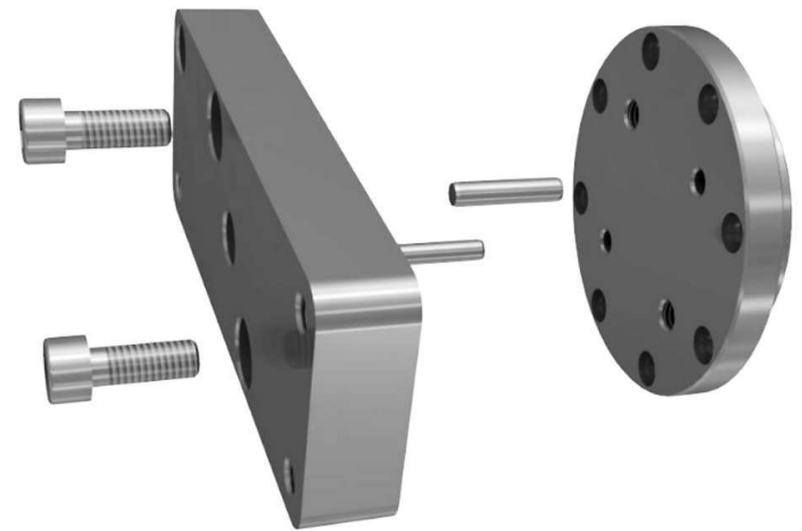

Fig. 5 Exploded view of designed robot flange

Round part of flange assembly is designated to be mounted directly on the end of robot's arm. For different types of robots, it is necessary to adjust design so that it can be applied to the chosen manipulating device. It is necessary to adjust the layout of the flange clamping holes to the end of robot's arm and also the fitting diameter by which it's precisely aligned with the end of robot's arm. These dimensions and also tolerances of the fitting are defined directly by the robot manufacturer for a particular model.

The rectangular part carries one part of coupling system and ensure its precise and firm clamping during the pallet handling process. Shape and dimmensions of this part are depending on the shape of the NSR mini 100 part of the chosen coupling system and by layout of its mounting holes. Dimensional and geometric accuracy of this part are defined in the operation manual part of the manufacturer's catalog.

\subsection{Technological pallet}

The shape of the technological pallete designed for the described system of automatic workpiece clamping implements an untraditional shape (Fig. 6). The main reason for the usage of this unique non-flat shape of palett with rised ends is to reduce height occupied by the system and thus maximize workspace awailable in machine tool. Lots of attention was paid to the least possible distance of the pallet clamping surface from the worktable surface of the machine. With these requirements on mind, the final pallets dimensions are $402 \times 125 \times 34 \mathrm{~mm}$ and the pallet clamping surface has dimmensions of $266 \times 125 \mathrm{~mm}$ with active thickness $20 \mathrm{~mm}$. There are also designed the mounting holes on the pallet surface for the purpose of clamping workpieces or another clamping devices. These holes are the combination of threaded holes M8, used for mounting screws, and precise holes $\phi 8 \mathrm{H} 7$ for clamping and aligning pins.
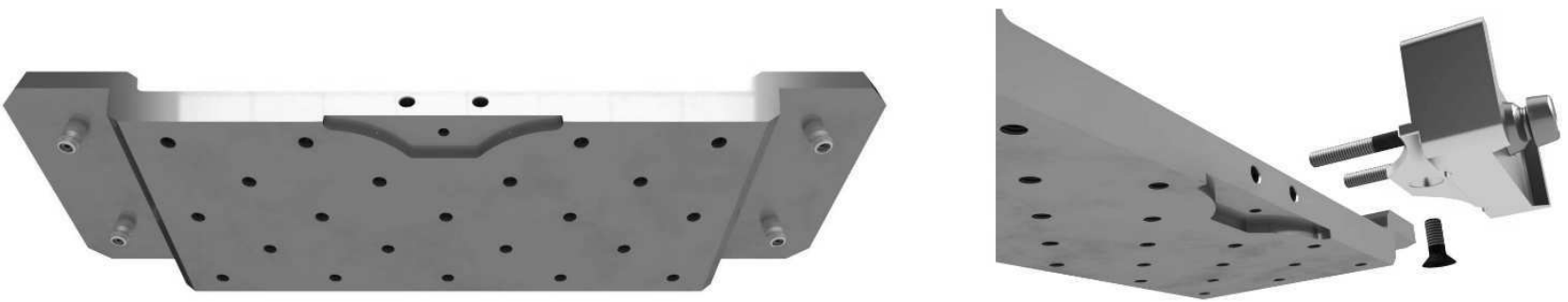

Fig. 6 Detailed view of pallet modifications

Besides the new parts mentioned above, the coupling system proposed in this article requires also some minor modifications of the original design of the technological pallet itself. Basic dimensions and the layout of the mounting holes for workpiece clamping remained the same. However, in order to achieve a reliable fixation of the robot coupling system on the pallet and at the same time ensure minimum possible height of pallet, there is a recess milled on the bottom side of pallets body. This recess shape exactly copies the shape of supporting surface of robot coupling system PKL mini 100 and in combination with three mounting screws it provides accurate and safe assembly to the proposed technological pallet. There are two horizontal threaded holes M6 with depth of 55 $\mathrm{mm}$ designed on one side of the pallets body suitable with robot coupling system mounting screws. Also one of the threathed holes for mounting screws is changed from M8 to M6 to ensure a suitable mounting.

Fixed handles designed for the manual handling of the pallet are no longer necessary, therefore they were removed from the design. However, in case of emergency there can be used detachable handles for manual handling. Handles can be attached to four Allen screws M8 x 25 STN 02114352 partially screwed to mounting threaded holes located on the pallets workpiece mounting surface. On the other hand, improved design should allow to manipulate the technological pallets with industrial robot with serial kinematic structure.

All constructional modifications on technological pallet have to be done in high geometrical, dimensional, and positional precision to ensure accuracy of relative possitions of all parts of the clamping system. 


\section{Conclusion}

The above mentioned modifications of the interchangeable technological pallets system were designed to be implemented on the educational milling machine tool EMCO Concept Mill 105. This particular machine is a part of the laboratory of $\mathrm{CNC}$ machine tool programming at the department of Automation and manufacturing systems and in article described changes should allow implementation into a flexible production cell. These modifications can also, if necessary, allow the machine to be connected to a more complex flexible production system with other machines at its workplace.

The presented system is designated for a specific milling machine, but if it's required, after applying another necessary adjustments or modifications, it can be easily applied to analogous $\mathrm{CNC}$ machines from other manufacturers, where the main limitations are the machine workspace dimensions.

Elaborated design is a task which brings a great deal of improvement in teaching and, in particular an increase in workplace technical level. With such a system equipped, the workplace will be also more complex and it will therefore be closer to the realistic application of the device in the industrial production line. This particular design would allow an adequate solution of special tasks related to automation, robotics and also to technical device diagnostics.

As a further advantage of the proposed modifications can be mentioned the increased usability of previously designed technological pallet with unusual non-flat design with raised ends on both sides. Benefit of the whole design is the possibility of its use as the real life example of automatic workpiece exchange for educational purposes at the university within the simple flexible production cell.

\section{Acknowledgement}

This article was made under support of project: STIMULY MATADOR 1247/2018. Project title: Research and de-velopment of modular reconfigurable production systems using Smart Industry principles for automotive with pilot application in MoBearing Line industry.

\section{References}

[1] WALSH, R. A., CORNIER, D. R., (2006). McGraw-Hill machining and metalworking handbook. New York: The McGraw-Hill Companies, Inc., 2006, 3. vydanie. 976 s. ISBN 0-07-1457879

[2] GROOVER, M. P., (2000). Automation, Production Systems, and Computer-Integrated Manufacturing. New Jersey: Prentice Hall, 2000. 867 s. ISBN 978-01-308-8978-2
[3] KANDERA, M. (2017). Design of clamping system for EMCO Concept Mill 105, (in Slovak), Master's thesis, University of Žilina (2017)

[4] EMCO GmbH, Technical specification Concept MILL 105, http://www.amsarg.com.ar/Productos/EMCO/spec_cm105_en.pdf

[5] KORZEKWA, J., WAWRZAŁA, P., SKULSKI, R. (2008). Electromechanical properties of PLZT x/90/10. In: European Physical Journal - Special Topics, 154 (1), pp. 127-130. DOI: 10.1140/epjst/e2008-00530- 5.

[6] BULEJ, V., URÍČEK, J., POPPEOVÁ, V., ZAHORANSKÝ, R., RUPIKOVÁ, M. (2013). Study of the workspace of hybridmechanism Trivariant. In: Applied mechanics and materials. ISSN 1660-9336. - Vol. 436, 2013. s. 366-373.

[7] STUSEK, J., MACEK, T. (2015). Design of Experiments for CNC Turning. In: Manufacturing Technology. ISSN 1213-2489. Vol. 15, No. 3, 2015. p. 448-455

[8] CÍSAR, M., et al. (2017). Design of the clamping system for the CNC machine tool. In: MATEC Web of Conferences. EDP Sciences, 2017. p. 01003 .

[9] KURIC, I., BULEJ, V., SÁGA, M., POKORNÝ, P. (2017). Development of simulation software for mobile robot path planning within multilayer map system based on metric and topological maps. In: International journal of advanced robotic systems. ISSN 1729-8814. - Vol. 14, iss. 6, 2017. online, 14 S.

[10] PALAŠČĆKOVÁ, D., DEMEČ, P. (2016). Measurement precision KUKA robots move at a defined distance and proposal for a robotized workplace to support the learning process. In: Manufacturing Technology. ISSN 12132489. Vol. 16, No. 6, 2016. p. 1344-1350

[11] STANČEK, J., BULEJ, V. (2015). Design of driving system for scissor lifting mechanism. In: Academic journal of manufacturing engineering. ISSN 1583-7904. - Vol. 13, no. 4, 2015. s. 38-43.

[12] SKULSKI, R., WAWRZAŁA, P., KORZEKWA, J., SZYMONIK, M. (2009). The electrical conductivity of PMN-PT ceramics. In: Archives of Metallurgy and Materials, 54 (4), pp. 935-941.

[13] SCHUNK GmbH \& Co. KG., Quick-change Pallet Systems, https://schunk.com/fileadmin/ pim/docs/ IM0010412.PDF.

[14] KOSINAR, M., KURIC, I. (2011). Monitoring possibilites of CNC machine tools accuracy. In: Proceedings of 1st International Conference on Quality and Innovation in Engineering and Management (QIEM), 17-19.3.2011, p. 115-118 